\title{
Maxillary Distraction Osteogenesis
}

\author{
Mohammad-Esmaiil Hassani ${ }^{1}$, Hamid Karimi ${ }^{1}{ }^{*}$, Hosein Hassani², Ali Hassani ${ }^{3}$ \\ ${ }^{1}$ Faculty of Medicine, Iran University of Medical Sciences, Tehran, Iran \\ ${ }^{2}$ Family Practice, Davis University, Modesto, USA \\ ${ }^{3}$ Internal Medicine, North Bay Medical Center, Fairfield, USA \\ Email: ${ }^{\text {hamidkarimi1381@yahoo.com }}$
}

Received 11 January 2015; accepted 30 January 2015; published 2 February 2015

Copyright (C) 2015 by authors and Scientific Research Publishing Inc.

This work is licensed under the Creative Commons Attribution International License (CC BY). http://creativecommons.org/licenses/by/4.0/

(c) (i) Open Access

\section{Abstract}

Background: Distraction Osteogenesis is popular for long bones. And nowadays it has found its role in facial bone deficiency treatments. Purpose: We used our special designed Distractor for advancement of Maxillary deficiencies in cleft lip and palate patients. The purpose of this paper is to compare the treatment of hypoplastic, posteriorly retruded maxillary of cleft palate patients using distraction osteogenesis vs. Le fort I orthognathic surgery for length of advancement, stability and relapse, growth after distraction and soft tissue expansion and soft tissue profile changes. Meterial \& Methods: In group A only Le fort I and surgical maxillary advancement sometimes with bone graft were done. In group B we used our special Distractor for Distraction Osteogenesis and advancement of the Maxillary bone. Demographic data, length of retrusion of maxilla, time length of treatment, length of advancement and relapse, SNA and SNB angles were measured and included in the study. The results were compared in each group before and after advancement and between both groups. The rate of distraction was $0.5 \mathrm{~mm}$ twice per day to achieve normal occlusion with $2 \mathrm{~mm}$ overcorrection more than calculated measures. The devices removed after 10 weeks as latency period. Results: The SNA increased at the end of distraction $(p<0.001)$, with no significant relapse indicating stability at 1 year after treatment. The total length of advancement in group $A$ was $17 \pm 4 \mathrm{~mm}$ and in group $B$ was $20 \pm 3 \mathrm{~mm}$. The difference between before and after measurements in each group was significant ( $p=0.002, p=0.003$ respectively). The mean length of relapse in group A was $3 \pm 1 \mathrm{~mm}$ and in group B was $1 \mathrm{~mm}$. Discussion: For the deformities and retrusions less than $7-8 \mathrm{~mm}$, the Orthognatic surgery is the treatment of choice, however for more retrusions $(>10 \mathrm{~mm})$ we recommend Distraction Osteogenesis, and it preferred to start it soon in younger ages.

\section{Keywords}

Maxilla, Retrusion, Distraction, Osteogenesis, Relapse

\footnotetext{
${ }^{*}$ Corresponding author.
} 


\section{Introduction}

Cleft lip and palate patients have many problems in Maxilla and Mandible and their face has multiple bony deformities. Multidisciplinary treatment planning and sequentially staged treatment is essential for successful patient outcomes. Besides the surgical osteotomies, recently, distraction osteogenesis has become an irreplaceable part of the surgical armamentarium, for its ability to induce new bone formation between the surfaces of bone segments that are gradually separated by gradual traction, along with a simultaneous expansion of the surrounding soft-tissue envelope [1].

\section{Materials \& Methods}

During more than 8 years we had 79 patients with maxillary retrusion due to cleft lip and palate. The patients and/or their parents signed an informed consent about the procedures and treatments.

In group A only Le fort I and surgical maxillary advancement sometimes with bone graft were done. In group B we used our special Distractor for Distraction Osteogenesis and advancement of the bone.

X-Rays, cephalogram, photography and sometimes CT scan were done before and after surgery for the patients. Demographic data, length of retrusion of maxilla, time length of treatment, length of advancement and relapse, SNA and SNB angles were measured and included in the study. The results were compared in each group before and after advancement and between both groups. Distraction begins 5 days after operation by increment of $1 \mathrm{~mm} /$ day (0.5 mm twice a day).

The end of distraction was transforming class III occlusion to class I occlusion or advancement of $2 \mathrm{~mm}$ more than it was calculated.

SPSS software was used for data analysis and $p$ value less than $0.05 \%$ was considered significant.

\section{Results}

During more than 8 years we had 79 patients with history of cleft lip and palate. For 47 patients in group A, Le fort I technique and maxillary advancement were done. And in group B for 32 patients Distraction Osteogenesis were done (Pictures 1-3).

X-Ray and cephalograms of patients showed good to excellent occlusion (Pictures 4-7).

In all patients soft tissue profile got better and normalized (Picture 8, Picture 9).
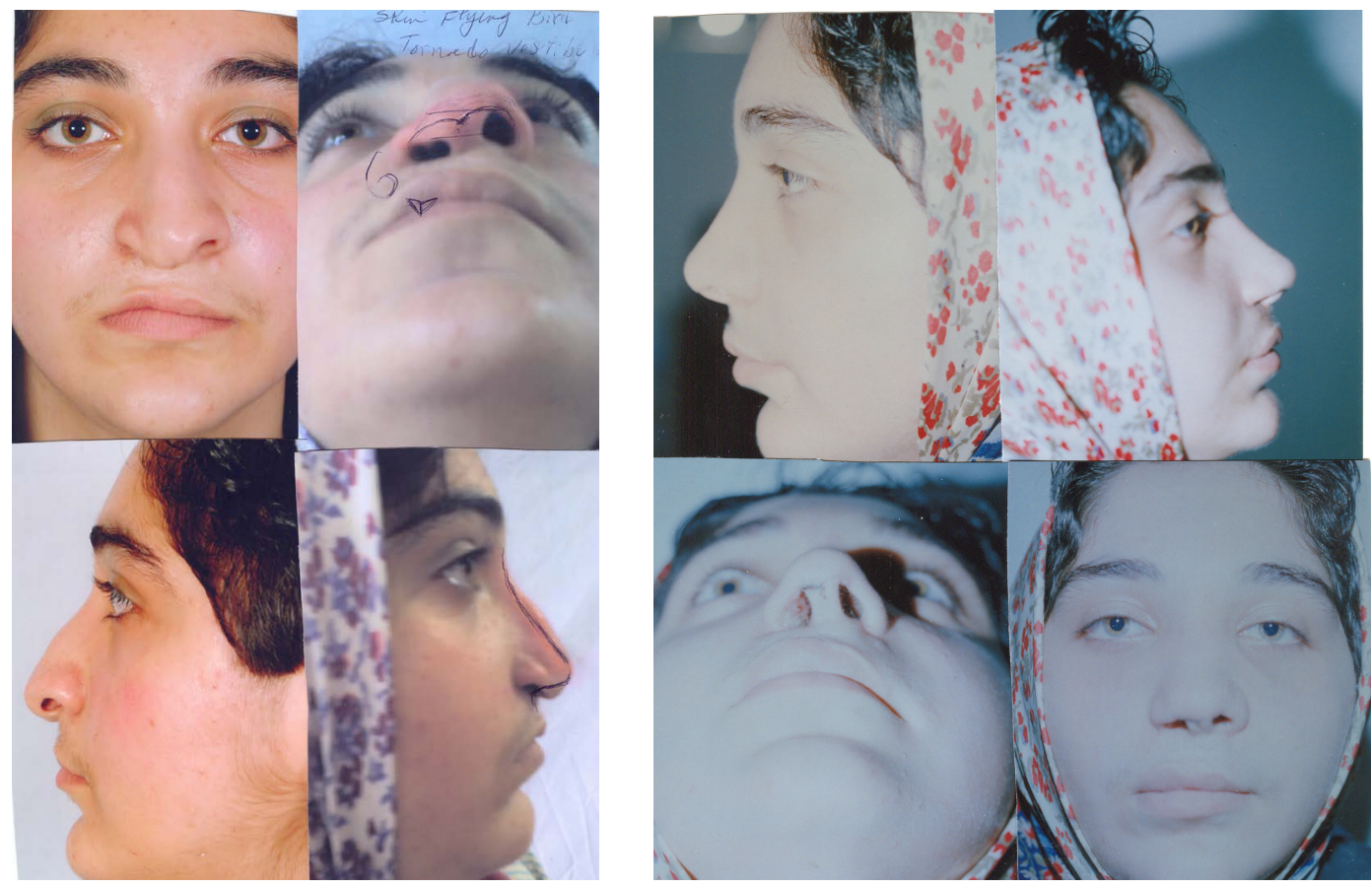

Picture 1. Maxillary advancement in a 16 years old girl with history of cleft lip. note correction of occlusion. 

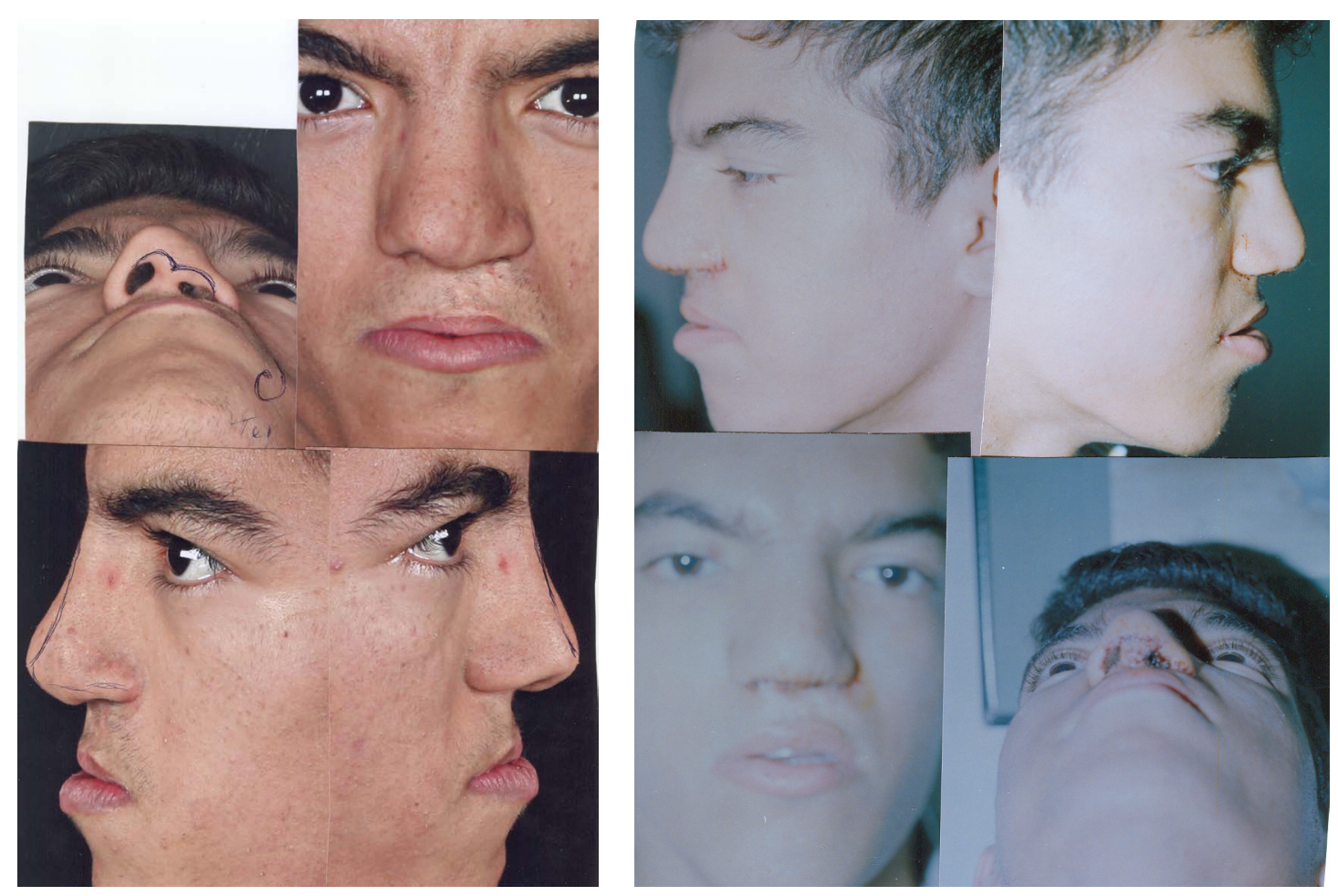

Picture 2. Maxillary advancement with Le Fort I technique (without Distraction) in a 15 years old boy.
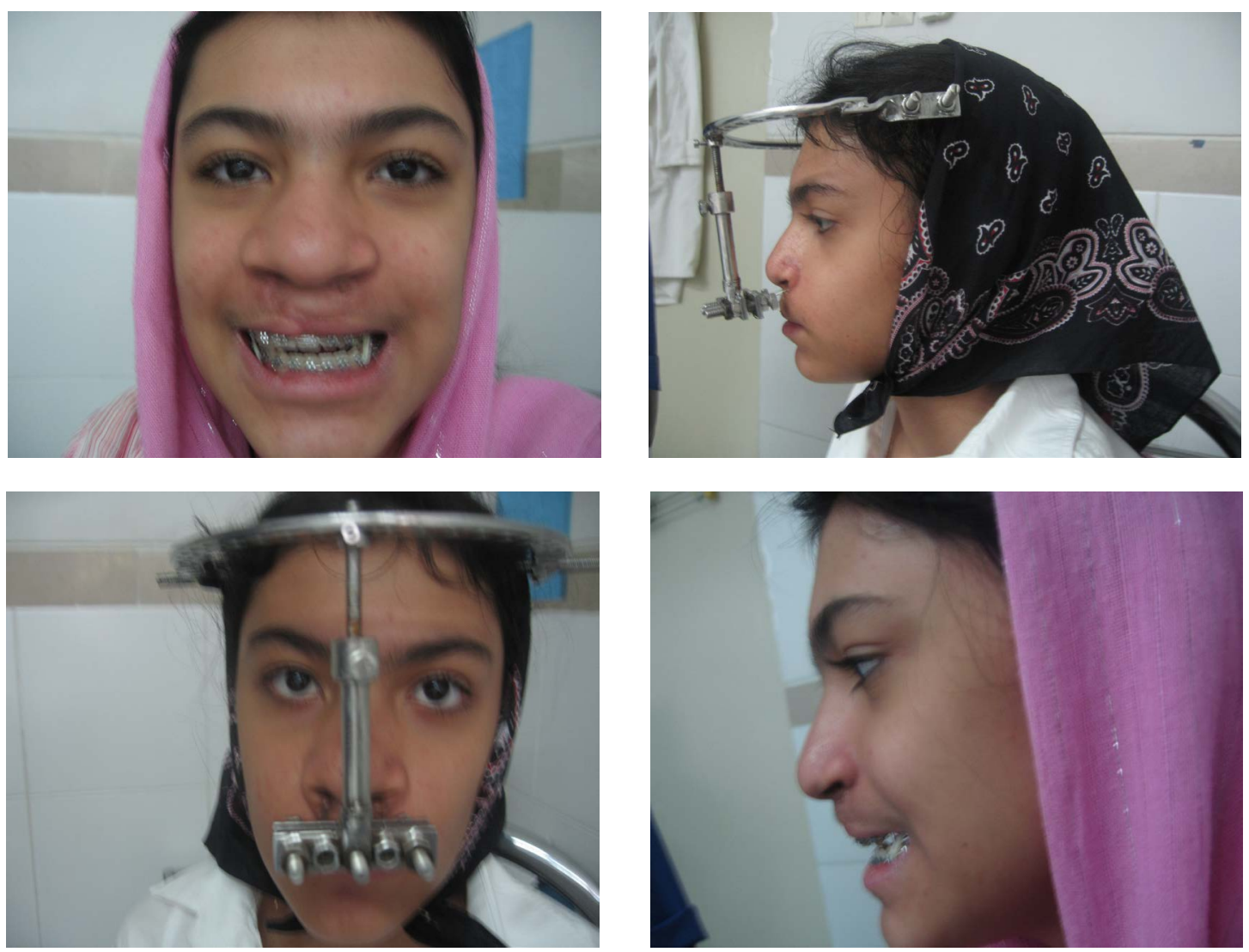

Picture 3. Distraction osteogenesis device (external type). 


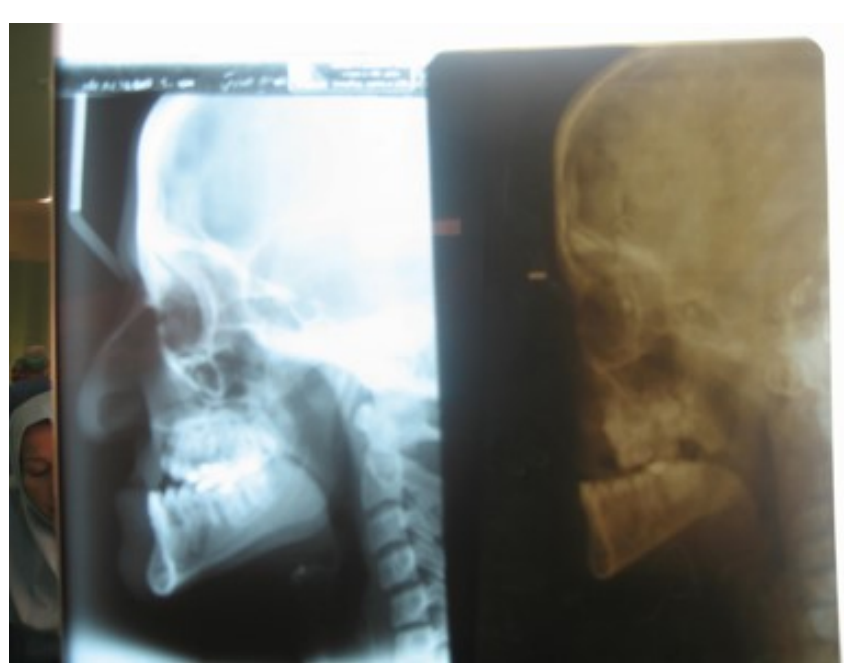

Picture 4. Lateral Cephalograms, before and after distraction, note the correction of teeth occlusion.

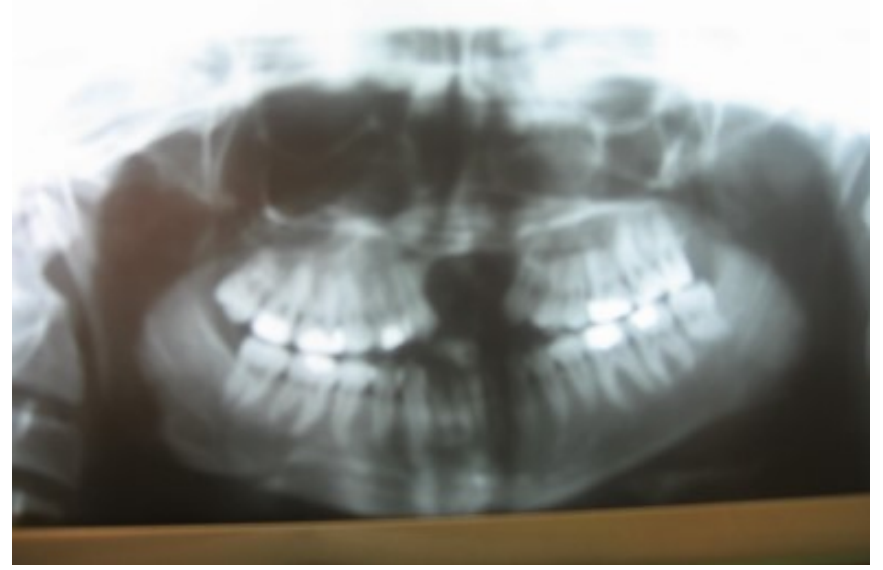

Picture 5. OPG before treatment.

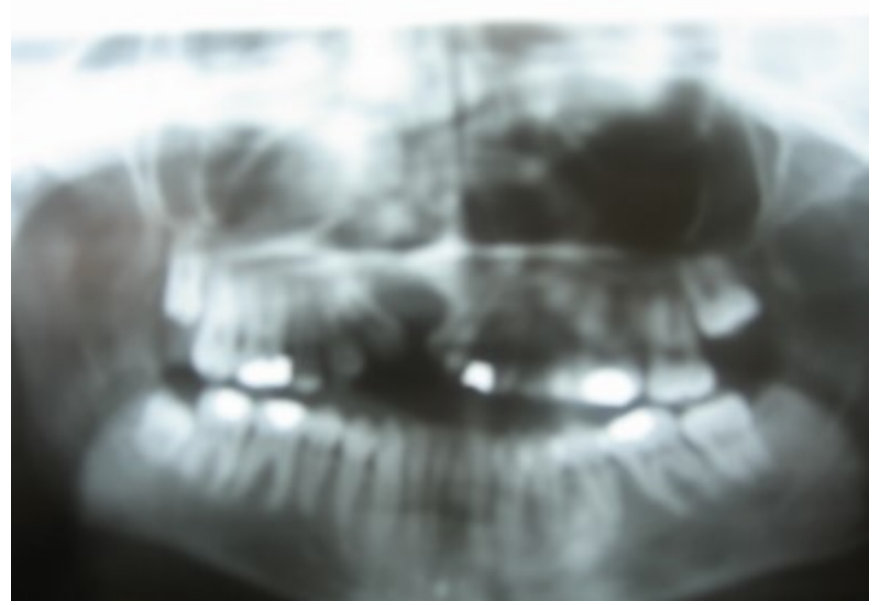

Picture 6. OPG after treatment. 


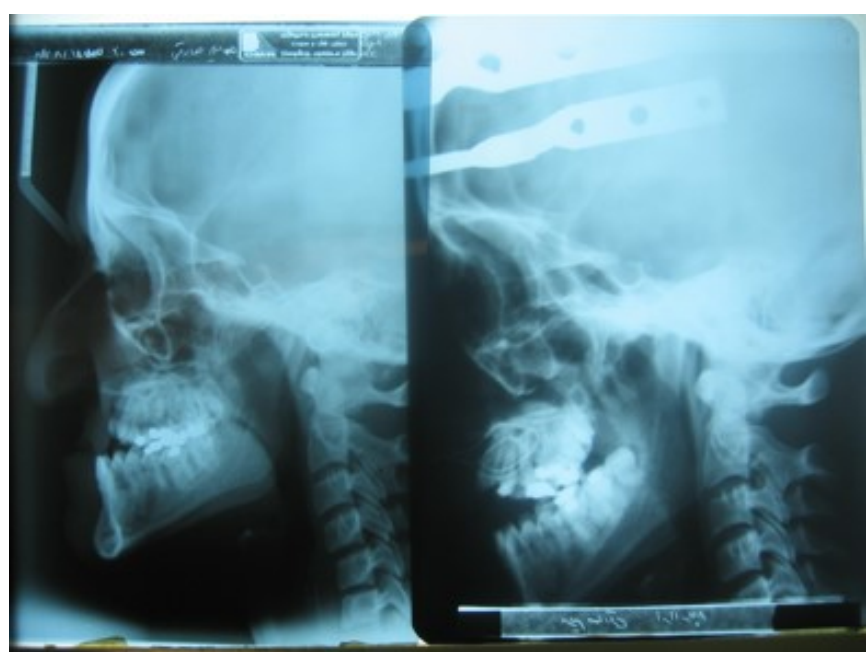

Picture 7. Lateral Cephalogram before and after treatment, note open bite after treatment.

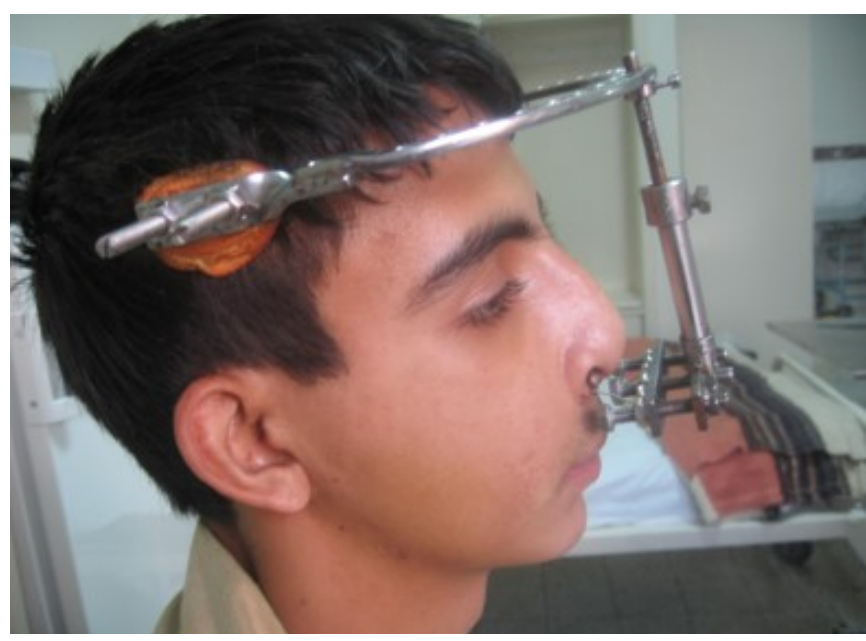

Picture 8. A 12 years old boy and external distraction osteogenesis device.

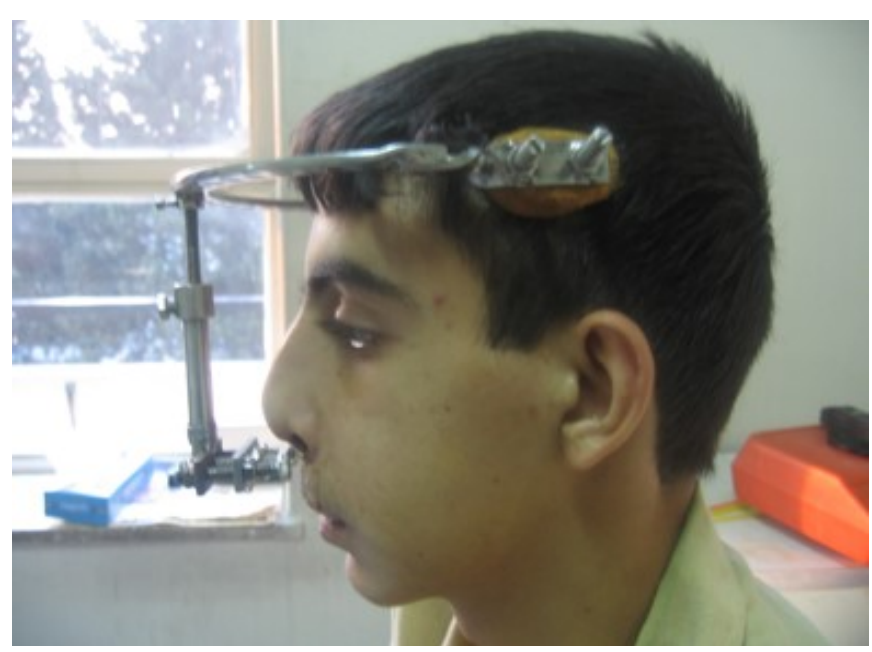

Picture 9. The same patient as in Picture 8. 
The mean \pm SD of age in group A was $23.5 \pm 5$ years and in group B was $15 \pm 4$ years.

The mean \pm SD of the length of retrusion in group A were $17 \pm 5 \mathrm{~mm}$. And in group B it was $19 \pm 6 \mathrm{~mm}$.

Total length of treatment for patients in group A from first visit to the end of process and maxillary advancement was 30 days and in group B was 45 days.

The SNA increased at the end of distraction $(\mathrm{p}<0.001)$, with no significant relapse indicating stability at 1 year after treatment. However SNB, facial angle, gonial angle, and symphyseal angle remained stable.

The total length of advancement in group A was $17 \pm 4 \mathrm{~mm}$ and in group B was $20 \pm 3 \mathrm{~mm}$.

The difference between length of retrusion of maxilla before the treatments in both groups were not significant.

Although the difference between before and after measurements in each group was significant $(p=0.002, p=$ 0.003 respectively).

The difference between before and after the treatments of both types was not significant.

The mean length of relapse in group A was $3 \pm 1 \mathrm{~mm}$ and in group B was $1 \mathrm{~mm}$.

\section{Discussion}

The use of new surgical method such as distraction osteogenesis to generate bone is becoming the preferred method for treatment of a variety of craniofacial and endochondral bone deficits. This technique relies on the endogenous cellular efficacy of the host to promote bone formation and remodeling and offers a number of advantages over traditional techniques of skeletal deficiencies. For example bone formed by these techniques is in general of better quality and is less susceptible to relapse. This may be attributed in part to the accompanying changes in the soft tissue envelope thus enabling its expansion to accommodate the newly formed bone.

Distraction osteogenesis is the generation of viable bone by the gradual separation of osteotomized bone edges. The roots of distraction osteogenesis can be traced to the late 19th century when the treatment of shortened limbs by osteotomy follow by acute lengthening and bone grafting was first described. During the later decades, enthusiasm for these procedures waxed and waned as clinical needs resulting.

From World War 2 injuries and the polio epidemic were offset by the requirement for multiple operative procedures, a significant incidence of complications, and the need for subsequent bone grafting.

In a novel observation, Dr. Ilizarov, a Russian orthopedic surgeon, noted the spontaneous generation of bone when an external fixator designed to compress bone ends was accidentally distracted at a slow rate.

This observation led to a series of experiments with use of the canine tibia and hundreds of clinical cases in which Ilizarov identified the biomechanical factors responsible for bone formation in distraction osteogenesis and established guidelines that result in the production of viable bone in a majority of cases [2]-[4].

Variables Affecting Osteogenesis are age, Blood supply, latency period, rate of distraction, frequency of distraction, site of distraction, stability of devices and fixation period.

The negative effects of aging on fracture healing and distraction osteogenesis have been well described. In clinical practice, fractures heal most rapidly in infants; healing rates decrease steadily until skeletal maturity, reaching a plateau thereafter. The increased fracture healing rate in infants and children translates to a distractionhealing index (a measure of regenerate bone ossification rate) that is nearly twice that of adults [5].

Factors influencing blood supply to distracted bone segments are known to have significant effects on osteogenesis. These findings are not surprising given the fact that osteocyte survival requires proximity of less than O.I mm to nutrient vessels. Osteogenesis during distraction is in general similar to fracture repair process and is dependent on angiogenesis, surgical technique can significantly alter the blood supply to distracted bone segments and may contribute to variability in the outcomes of experimental and clinical distraction osteogenesis. These changes are most prominent in long bones because their blood supply is less vigorous than that of the bones of the craniofacial skeleton. So we have better situation for distraction of facial bones (Figure 1).

Schematic of the stages of bone formation during distraction osteogenesis is as below:

1) zone of fibrous tissue;

2) zone of extending bone formation;

3) zone of bone remodeling;

4) zone of mature bone.

Most experimental evidence suggests that optimal osteogenesis is obtained when distraction is delayed 5 to 7 days after osteotomy. This time interval is termed the "latency period". In general, shorter latency periods tend 


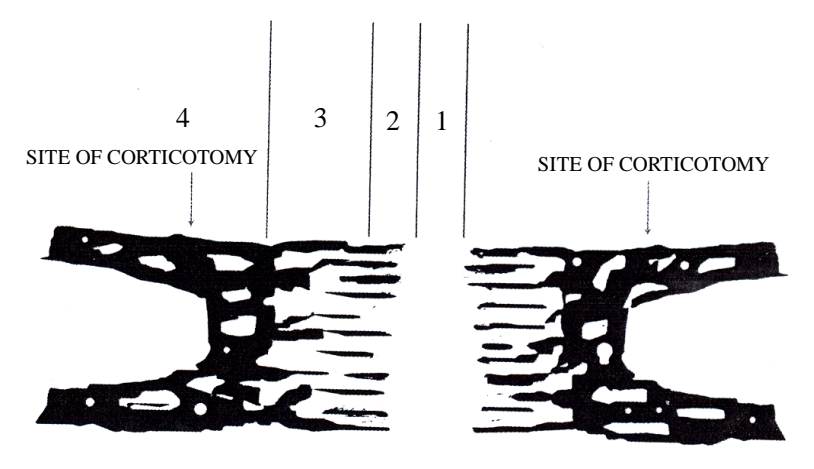

Figure 1. Site of corticotomy.

to generate smaller callus volumes and result in inadequate osteogenesis, whereas longer periods (i.e.: >14 days) are associated with premature consolidation. Histologic studies have demonstrated that callus volume and capillary in growth are increased with a short delay before the initiation of distraction. Several factors may account for the impaired osteogenesis resulting from immediate distraction protocols. For example, disruption of the fracture hematoma, as may occur with immediate distraction, is associated with a $26 \%$ decrease in callus crosssectional area and results in significantly decreased mechanical strength.

Numerous studies have investigated the effects of varying the rate and frequency (rhythm) of distraction on regeneration of bone formation. Although ideal distraction rates and frequencies depend on multiple factors, in general, optimal endochondral bone formation in large animal models occurs at a rate of approximately 1.0 $\mathrm{mm} /$ day. In a series of 400 canine tibial lengthening experiments comparing distraction rates of 0.5, 1.0 and 2.0 $\mathrm{mm} /$ day, Ilizarov demonstrated that distraction at the lowest rate was frequently complicated by premature consolidation, whereas distraction at a rate of $2.0 \mathrm{~mm} /$ day often resulted in inadequate bone formation and fibrous union. In contrast, distraction at a rate of $1.0 \mathrm{~mm} /$ day consistently resulted in spontaneous osteogenesis with excellent bone stock in virtually all cases.

Stable fixation of osteotomized bone segments is a Critical factor in distraction osteogenesis. Comparison of canine tibial osteotomies distracted with devices that had varying degrees of stability revealed Significantly enhanced osteogenesis with secure fixation and on the other hand nonunion with pseudarthrosis formation with unstable devices. Even slightly decreased stability was deleterious and resulted in a significant increase in full remodeling time. The distraction is followed by an $8-12$ weeks consolidation phase to allow for shaping and molding of the bone [2].

Many devices have been designed for mandibular and craniofacial distraction with varying rates and success. But they are expensive and sometimes too complicated to be used easily. Distractors are too expensive which the patient cannot afford to use it for their deformity.

In our Hospital we used a special designed device for Distraction of Maxilla. Patients are those with cleft lip and palate. The device is somehow simple, easy to install and use, light weight and cheap. It is made from stainless steel and can be sterilized for multiple usage and has blunt edges.

Most cleft lip and palate patients have hypoplastic maxilla at 16 years of age and need maxillary osteotomy and correction facial deformity.

In our patients the device had a good result with more than $20 \mathrm{~mm}$ advancement and good dental occlusion, good soft tissue expansion and coverage and patients could easily tolerate it.

The relapse after one year was less than $1 \mathrm{~mm}$ and mostly in non-cooperative patients who fail to come for regular follow up visits comparing to group A patients with $3 \mathrm{~mm}$ relapse.

This method also prevents velopharyngeal incompetency and deterioration of the function of the velom [6].

We had only 2 patients who had not enough advancement and a second surgery were needed for further correction of the deformity (Le fort I and bone graft).

Our results showed that maxillary advancements achieved by distraction are more stable than those achieved with orthognathic surgery with a minimal influence on velopharyngeal competence as with the other reports [3] [7].

There are some other reports about distraction for example Metzler in 2005 reported that the alar width and alar base width after 6 months is expanded. The magnitude of nasal change parallels that of expansion at the py- 
riform aperture [8].

Some authors also used DO for closure of cleft palate [9].

In another report by Doucet in 2014 he found that the shape of the mandible is stable. He showed that in long-term the mandible demonstrated a minimal counter-clockwise rotation of the body and ramus. The maxillary advancement remained stable after 1 year [10].

Also Rattan in 2014 reported that the advancement of maxilla by distraction osteogenesis at Le Fort-I level induced significant bone apposition at infraorbital rim. It means that patients with mild midface hypoplasia who would otherwise may be candidates for osteotomy at Le Fort-II or Le Fort-III level may benefit from maxillary distraction at Le Fort-I level [11].

There is another report by Sant Anna that the rigid external distraction device (RED) is successfully used to advance the maxilla and all the maxillary-orbital-frontal complex (monobloc) in children, adolescents and adults.

This approach provides predictable and stable results [12]. This results are the same as ours and proved efficacy of this method.

Also in tumors abalation one can use transport DO [12].

Janardhan reported that Advancement of the anterior maxilla alone without interfering with the velopharyngeal sphincter may be advantageous in cleft patients, who more commonly have speech deficits and dental crowding. He presented a case series of anterior maxillary segmental distraction for maxillary hypoplasia and not any deterioration in speech [13]. the same has been found in our study and a stable occlusion with positive overjet and correction of dental-crowding without extraction was achieved at one year follow up.

In an important paper Doucet found that growing patients showed greater rotations of their palatal plane and mandibular plane.

Therefore Maxillary DO in CLP does not correct the growth deficit inherent to the pathology. Overcorrection of at least $20 \%$ is advised during growth [14].

In our study we used this percentage for ending of distraction.

Also in other reports it is stated that in the rigid external device patients the maxilla was advanced an average of $15.80 \mathrm{~mm}$. The occlusion changed from class III to class I. The profile of the face changed from concave to convex. At a 1-year follow up the results were stable.

So these authors concluded that in mild maxillary deficiency a one stage orthognathic surgery is preferable. However, in patients requiring moderate to large advancements with significant structural deficiencies of the maxilla or in growing patients the distraction technique is preferred [15]. It is also advisable from our results that for better self-steem and sooner result in a growing child, it is better start the distraction from a lower age and the child would have a normal face sooner. Also in lower ages the child has better ability to grow a better and stronger bone.

\section{Conclusion}

Distraction Osteogenesis is an effective method for Maxillary hypoplasia and improving function, aesthetics, and stability for cleft patients with multiple missing teeth. A well-balanced facial profile and a good alignment of the dentition were obtained. The patients had considerable improvement in his self-esteem. And it is advised to start the correction of deformity as soon as possible.

\section{References}

[1] Schendel, S.A., Hazan-Molina, H. and Aizenbud, D. (2014) Combined Orthognathic Distraction Procedure: Le Fort I Maxillary Osteotomy and Mandibular Curvilinear Distraction Osteogenesis. A New Technique for Craniofacial Management. Plastic and Reconstructive Surgery, 133, 874-877. http://dx.doi.org/10.1097/PRS.0000000000000055

[2] Natu, S.S., Ali, I., Alam, S., Giri, K.Y., Agarwal, A. and Kulkarni, V.A. (2014) The Biology of Distraction Osteogenesis for Correction of Mandibular and Craniomaxillofacial Defects: A Review. Dental Research Journal (Isfahan), 11, 16-26.

[3] Lucchese, A., Gherlone, E.F., Asperio, P. and Baena, R.R. (2014) The Distraction Osteogenesis in Midfacial Hypoplasia. Journal of Craniofacial Surgery, 25, 831-834. http://dx.doi.org/10.1097/SCS.0000000000000738

[4] Rachmiel, A., Even-Almos, M. and Aizenbud, D. (2012) Treatment of Maxillary Cleft Palate: Distraction Osteogenesis vs. Orthognathic Surgery. Annals of Maxillofacial Surgery, 2, 127-130. http://dx.doi.org/10.4103/2231-0746.101336 
[5] Corega, C., Vaida, L., Festila, D.G., Rigoni, G., Albanese, M., D’Agostino, A., Chiarini, G., Nocini, P.F. and Bertossi, D. (2014) Bimaxillary Distraction Osteogenesis Used for Treatment of Crowding in Non-Growing Individuals. Case Report. Minerva Stomatologica.

[6] Kim, B.C., Lee, S.H., Park, K.R., Jung, Y.S. and Yi, C.K. (2014) Reconstruction of the Premaxilla by Segmental Distraction Osteogenesis for Maxillary Retrusion in Cleft Lip and Palate. The Cleft Palate-Craniofacial Journal, 51, 240 245. http://dx.doi.org/10.1597/12-265

[7] Neelakandan, R.S. and Bhargava, D. (2012) Transport Distraction Osteogenesis for Maxillomandibular Reconstruction: Current Concepts and Applications. Journal of Maxillofacial and Oral Surgery, 11, 291-299. http://dx.doi.org/10.1007/s12663-011-0329-3

[8] Metzler, P., Geiger, E.J., Chang, C.C. and Steinbacher, D.M. (2014) Surgically Assisted Maxillary Expansion Imparts Three-Dimensional Nasal Change. Journal of Oral and Maxillofacial Surgery, 72, 2005-2014. http://dx.doi.org/10.1016/j.joms.2014.03.004

[9] Ghasemianpour, M., Ehsani, S., Tahmasbi, S., Bayat, M., Ghorbanpour, M., Safavi, S.M. and Mirhashemi, F.S. (2014) Distraction Osteogenesis for Cleft Palate Closure: A Finite Element Analysis. Dental Research Journal (Isfahan), 11, 92-99.

[10] Doucet, J.C., Herlin, C., Bigorre, M., Bäumler, C., Subsol, G. and Captier, G. (2014) Mandibular Effects of Maxillary Distraction Osteogenesis in Cleft Lip and Palate. International Journal of Oral \& Maxillofacial Surgery, 43, 702-707. http://dx.doi.org/10.1016/j.ijom.2014.01.017

[11] Rattan, V., Jena, A.K., Singh, S.P. and Utreja, A.K. (2014) Maxillary Distraction Osteogenesis at Le Fort-I Level Induces Bone Apposition at Infraorbital Rim. Clinical Oral Investigations, 18, 1741-1748. http://dx.doi.org/10.1007/s00784-013-1149-2

[12] Sant'Anna, E.F., Cury-Saramago, A.A., Lau, G.W., Polley, J.W. and Figueroa, Á.A. (2013) Treatment of Midfacial Hypoplasia in Syndromic and Cleft Lip and Palate Patients by Means of a Rigid External Distractor (RED). Dental Press Journal of Orthodontics, 18, 134-143. http://dx.doi.org/10.1590/S2176-94512013000400005

[13] Rao Janardhan, S., Kotrashetti, S.M., Lingaraj, J.B., Pinto, P.X., Keluskar, K.M., Jain, S., Sone, P. and Rao, S. (2013) Anterior Segmental Distraction Osteogenesis in the Hypoplastic Cleft Maxilla: Report of Five Cases. Sultan Qaboos University Medical Journal, 13, 454-459.

[14] Doucet, J.C., Herlin, C., Bigorre, M., Bäumler, C., Subsol, G. and Captier, G. (2013) Effects of Growth on Maxillary Distraction Osteogenesis in Cleft Lip and Palate. Journal of Cranio-Maxillo-Facial Surgery, 41, 836-841. http://dx.doi.org/10.1016/j.jcms.2013.01.038

[15] Rachmiel, A., Even-Almos, M. and Aizenbud, D. (2012) Treatment of Maxillary Cleft Palate: Distraction Osteogenesis vs. Orthognathic Surgery. Annals of Maxillofacial Surgery, 2, 127-130. http://dx.doi.org/10.4103/2231-0746.101336 
Scientific Research Publishing (SCIRP) is one of the largest Open Access journal publishers. It is currently publishing more than 200 open access, online, peer-reviewed journals covering a wide range of academic disciplines. SCIRP serves the worldwide academic communities and contributes to the progress and application of science with its publication.

Other selected journals from SCIRP are listed as below. Submit your manuscript to us via either submit@scirp.org or Online Submission Portal.
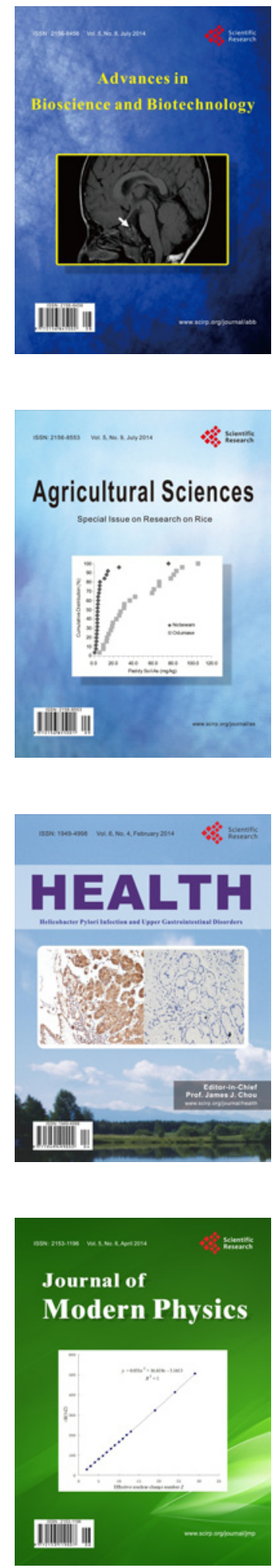
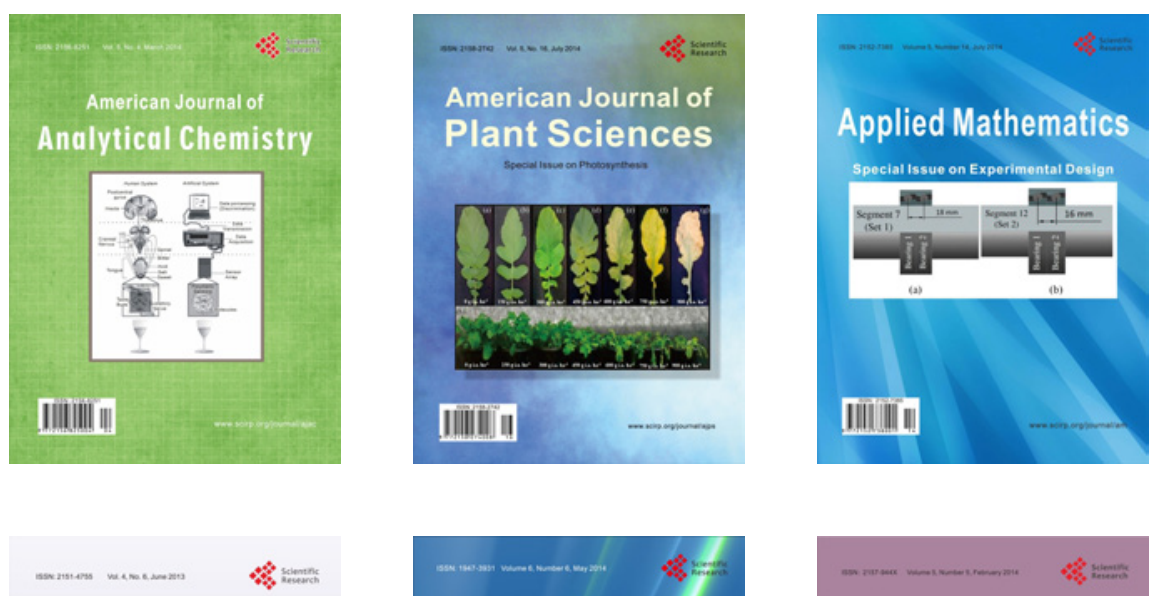

Creative Education
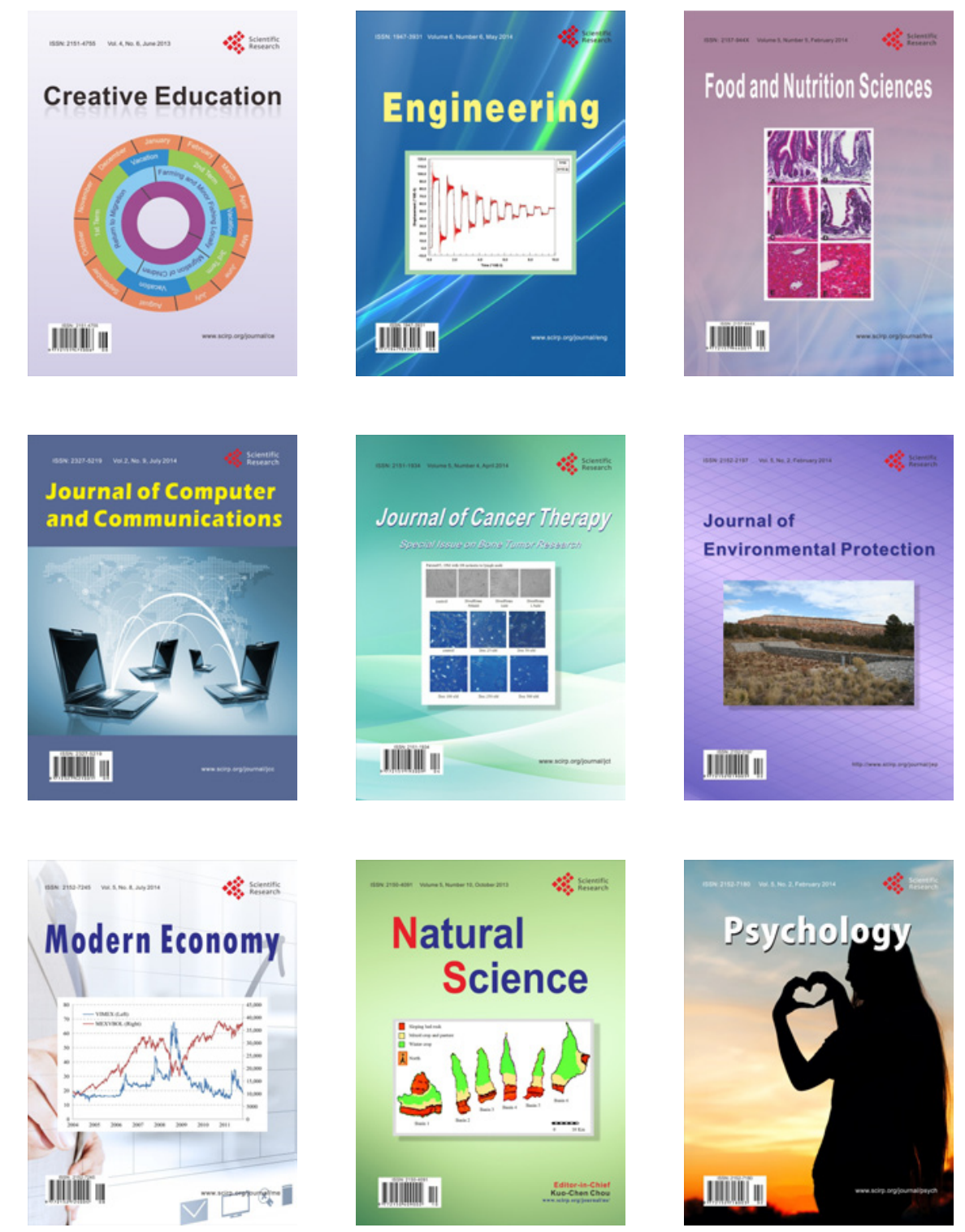